\title{
A new insight into phagocytosis of apoptotic cells: proteolytic enzymes divert the recognition and clearance of polymorphonuclear leukocytes by macrophages
}

\author{
K Guzik', M Bzowska', J Smagur², O Krupa ${ }^{1,2}$, M Sieprawska², J Travis ${ }^{3}$ and J Potempa ${ }^{\star, 2,3}$
}

The recognition of phosphatidylserine (PS) on the surface of any apoptotic cell is considered to be a key event for its clearance. We challenge this concept by showing that pretreatment of neutrophils with either host or bacterial protease affects their uptake by human monocyte-derived macrophages without having an effect on cell-surface PS presentation. Specifically, whereas preincubation of apoptotic neutrophils with cathepsin $\mathrm{G}$ or thrombin significantly inhibited their uptake, gingipains $\mathbf{R}$ or clostripain enhanced phagocytosis by macrophages. Moreover, bacterial proteinases sensitized healthy neutrophils for uptake by macrophages, whereas endogenous proteinases were unable to elicit this effect. This stimulation was apparently owing to the combined effect of proteolytic cleavage of an antiphagocytic signal (CD31) and the generation of a novel 'eat-me' signal on the neutrophil surface. These results argue that neutrophil recognition and phagocytosis by macrophages is mediated by a protein ligand whose proteolytic modification could affect the local inflammatory process.

Cell Death and Differentiation (2007) 14, 171-182. doi:10.1038/sj.cdd.4401927; published online 21 April 2006

Successful uptake of an apoptotic cell requires recognition of 'eat-me' signals exposed on the surface of the dying cell by specific receptors on macrophages. The best characterized system constitutes the recognition of phosphatidylserine (PS), which is relocated from the inner to the outer surface of the plasma membrane during apoptosis, by a specific PSreceptor (PS-R) on the phagocyte. Despite a growing body of evidence contradicting the absolute requirement of PS exposure for recognition of apoptotic cells by professional and/or amateur phagocytes, it is still generally accepted that PS plays a key role in successful clearance of apoptotic cells. ${ }^{1,2}$ In addition, according to a new paradigm, a two signal, 'tether and tickle' mechanism is involved in apoptotic cell clearance. ${ }^{3}$ Tethering can be provided by binding of a receptor on phagocytes with ligands on dying cells. A large variety of receptor molecules including PS-R, CD14, CD68, class A scavenger receptor, ATP-binding cassette transporter 1, complement receptors, integrin $\alpha_{v} \beta_{5}$, and $\alpha_{v} \beta_{3} /$ CD36/thrombospondin (TSP) complexes have been reported to participate in the recognition of apoptosis-specific ligands to mediate the clearance of apoptotic cells. ${ }^{4}$ These receptors interact either directly with their ligands or through bridging molecules, many of which are known as PS-binding proteins. ${ }^{5}$ Depending on the cell type, 'eat-me' signals include altered carbohydrates, oxidized lipids, and undetermined binding sites for
TSP and collectins (e.g. mannose binding lectin, surfactant protein $A$, and $C 1 q) .{ }^{6}$ Together with the panel of bridging molecules and recognition receptors, a complex interface is formed between the phagocyte and the target cell, recently referred to as the 'engulfment synapse'. 5 Owing to the modality of its components, it is postulated that the synapses are unique for each interacting cell type. Nonetheless, it is suggested that only the direct ligation of PS-R on phagocytes to PS delivers a 'tickle' sign indispensable for triggering an uptake of apoptotic cells. $^{7}$

The pathways of apoptotic polymorphonuclear leukocytes (neutrophil) (PMN) clearance must be extremely efficient as PMNs are one of the shortest-lived cells. In addition, they constitute the first line of antibacterial defense, hence it is critical that the circulating and tissue patrolling population of PMNs is always fully functional and ready to ingest and kill invading organisms. In humans, this state of constant readiness is sustained by a continuous supply of fresh cells released from the bone marrow into the blood stream at a rate of 10 million cells per minute. The half-life of PMNs in circulation is very short $(6 \mathrm{~h})$ and under homeostatic conditions, they are removed by the reticular-endothelial system of the spleen and the bone marrow ${ }^{8}$ or migrate into the tissues to meet their nemesis. At the inflammation foci, PMN numbers within the tissue can be extremely

\footnotetext{
${ }^{1}$ Department of Immunology, Faculty of Biotechnology, Jagiellonian University, Krakow, Poland; ${ }^{2}$ Department of Microbiology, Faculty of Biotechnology, Jagiellonian University, Krakow, Poland and ${ }^{3}$ Department of Biochemistry and Molecular Biology, University of Georgia, Athens, GA 30602, USA

*Corresponding author: J Potempa, Department of Biochemistry and Molecular Biology, University of Georgia, Life Science Bldg., Athens, GA 30602, USA.

Tel: + 706-542-1713; Fax: + 706-542-3719; E-mail: potempa@uga.edu

Keywords: apoptosis; bacteria; inflammation; gingipain; periodontitis; proteolysis; receptor

Abbreviations: BSA, bovine serum albumin; CG, cathepsin G; hMDM, human monocyte-derived macrophages; NE, neutrophil elastase; PS, phosphatidylserine; PS$\mathrm{R}$, phosphatidylserine receptor; MPO, myeloperoxidase; PMNs, polymorphonuclear leukocytes (neutrophils); PAR, protease activated receptor; RgpB, arginine-specific gingipain B; HRgpA, high molecular mass arginine-specific gingipain A; Kgp, lysine-specific gingipain; TUNEL, terminal dUTP nick end labeling

Received 15.6.05; revised 20.2.06; accepted 01.3.06; Edited by M Hengartner; published online 21.4.06
} 
high not only because of targeted influx from the circulation but also because their constitutive apoptotic pathway is delayed by local inflammatory mediators. This is apparently the case in inflammatory gum disease, where even in the minimally-inflamed gingiva, accumulation of $2.5 \times 10^{7} \mathrm{PMN} /$ $\mathrm{ml}$ is observed. ${ }^{9}$ At this perimeter, PMNs constitute the most important protection against bacteria embedded in dental plaque on the tooth surface. Consequently, even very mild forms of PMN dysfunction can predispose affected individuals to severe forms of periodontitis. ${ }^{10}$ However, it has also been well documented that tissue damage associated with periodontal disease is related to extensive accumulation of PMNs and the release of their destructive hydrolytic enzymes. ${ }^{11-13}$ In this context, it is interesting to note that large number of PMNs in gingival crevicular fluid are found at different stages of necrosis. ${ }^{14,15}$ This may indicate that either the apoptotic program or clearance pathways of dying PMNs are malfunctioning at periodontal sites.

Disturbance of uptake of the apoptotic PMNs can be pivotal to the level of tissue damage sustained as the nonphlogistic clearance of dying cells by phagocytes is thought to be critical for the final resolution of acute inflammation. It not only prevents the uncontrolled release of proinflammatory intracellular contents of dying PMNs, but also converts the macrophage phenotype from pro to anti-inflammatory. ${ }^{4}$ Although in the physiological state, more PMN apoptotic corpses than any other cell type must be removed constantly, the mechanism involved in this process is still controversial. It was suggested that non-stimulated macrophages are supposed to remove aged PMNs utilizing the $\alpha_{v} \beta_{3} /$ CD36/TSP complex. ${ }^{16,17}$ Conversely, it has been shown that glucanactivated macrophages clear apoptotic PMNs through the PS-PSR interaction. ${ }^{18,19}$ Over time, however, a significant mass of evidence emerged questioning the physiological significance of either of these two mechanisms. ${ }^{20-22}$ Both suggested mechanisms do not take into account that at the infection site, the clearance of dying PMN may occur in a highly proteolytic milieu. Indeed, periodontal disease-affected gingival tissues and fluids contain significant amounts of proteolytic activity released by periodontopathogens and host cells. In several cases, it was shown that the level of protease activity in the gingival crevicular fluid correlates with severity of periodontal disease. ${ }^{23-26}$ Consequently, in this report we have investigated the effect of proteolytic enzymes abundant in gingival crevicular fluid, both periodontopathogen- and host-derived, on PMN clearance by macrophages. Whereas preincubation of apoptotic PMNs with host-derived cathepsin $\mathrm{G}(\mathrm{CG})$ practically abolished their clearance by macrophages, Arg-Xaa specific proteases (gingipains R) of a major periodontopathogen, Porphyromonas gingivalis, exerted a divergent effect. They not only enhanced the uptake of dying cells, but also sensitized healthy PMNs for ingestion by macrophages in a PS-independent manner. Such a protease-induced change in PMN recognition and clearance may have an impact on periodontitis development. Moreover, against the current paradigm, PMN ingestion by human monocyte-derived macrophages (hMDM) can occur independently of PS exposure and in the same way, trigger anti-inflammatory responses.

\section{Results}

A high throughput quantitative assay for uptake of apoptotic PMNs by macrophages. To study the effect of proteolytic enzymes on the clearance of apoptotic PMN by macrophages, we have designed a novel method to measure the uptake of these cells. The assay is based on the detection of PMN-derived neutrophil elastase (NE) activity in macrophages that have engulfed PMNs. In preliminary experiments, we have determined that the level of $\mathrm{NE}$ activity does not change during spontaneous apoptosis of PMN (data not shown) in accordance with an earlier observation that NE activity is preserved during apoptosis of PMNs and that this enzyme does not leak from apoptotic cells. ${ }^{27}$ Furthermore, the level of endogenous NE activity of macrophages, ${ }^{28}$ estimated at a level of at least four orders of magnitude lower than that measured in PMNs, ${ }^{29}$ was found not to interfere with our assay. In this method, at a predetermined time point after coculturing of the cells, the hMDM monolayer was washed free of noningested PMNs and the whole culture lysed with detergent instead of being stained for myeloperoxidase (MPO) activity. Subsequently, the lysate was assayed for NE activity using chromogenic substrates. The level of NE activity was found to be proportional to the intensity of phagocytosis over a broad range of hMDM : apoptotic PMN ratios and the assay could detect as few as 50 ingested PMN (Figure 1). As expected, the uptake of fresh PMNs was negligible after their incubation with hMDM. At the ratio of hMDM : fresh PMN of $1: 20$, the NE activity never exceeded $15 \%$ of the activity determined in the lysate of the hMDM monolayers cocultured with the same ratio of apoptotic PMN.

In comparison with the conventional microscopy-based assay for the phagocytic index involving the histochemical staining and counting of macrophages for PMN-derived MPO

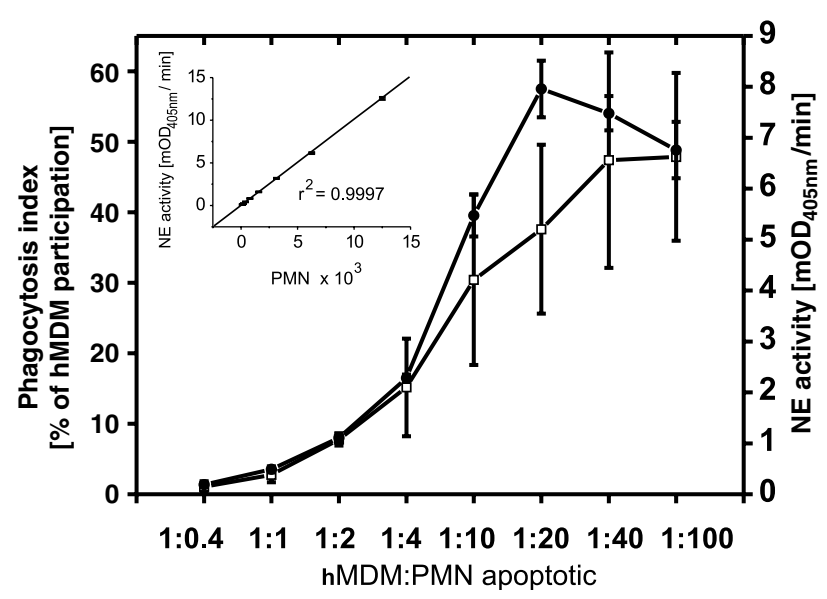

Figure 1 Quantification of phagocytosis of apoptotic PMNs based on NE activity as compared to the traditional MPO counting method. Phagocytosis was calculated as the mean percentage of MPO-positively stained macrophages (phagocytosis index; open squares) or expressed as increase of $\mathrm{OD}_{405} \mathrm{~nm}$ in milliunits per min $\left(\mathrm{mOD}_{405 \mathrm{~nm}} / \mathrm{min}\right)$ of $\mathrm{NE}$ activity in cell lysates (filled circles) over a range of macrophage : PMN ratios. Inset shows the linear correlation between NE activity and PMN numbers. The figure shows the mean data \pm S.D. from three representative experiments 
activity, the new NE assay correlated very well (Figure 1). Moreover, the NE-based assay was significantly more reproducible than the MPO staining method, especially at high hMDM : PMN levels. Also, it allowed for the detection and quantification of ingested PMNs even after they had been partially broken down by macrophages. Furthermore, in contrast to the tedious and time-consuming task of counting for PMN-engulfed macrophages, our method yields a fast, simple and objective determination of phagocytosis intensity on a large scale. The variability of the NE-based method, reflected by standard deviation in Figure 1 was significantly smaller than that of the classic assay, and was primarily due to differences in intracellular NE content in PMNs among blood donors and variation in the level of NE inhibitors in macrophages and/or PMN cytoplasm. ${ }^{30}$ In experiments with freshly isolated PMNs, the major contribution to the observed background was the percentage of spontaneously apoptotic PMNs in the circulation which also varies among donors.

Preincubation of PMNs with gingipains stimulates their phagocytosis. As application of the NE-based assay would be skewed if the test conditions cause PMN degranulation, we have first assessed the effects of $P$. gingivalis major proteinases on NE release by PMNs. At concentrations up to $500 \mathrm{nM}$, none of gingipains tested caused any significant NE release during $1 \mathrm{~h}$ incubation with $\mathrm{PMN}$ suspension (data not shown). Next, to determine the effect gingipains have on phagocytosis of PMNs by macrophages, both fresh and apoptotic PMN were preincubated with gingipains (high molecular mass arginine-specific gingipain A (HRgpA), arginine-specific gingipain $B(\mathrm{Rgp} B)$, and lysine-specific gingipain (Kgp)), followed by feeding to hMDM. Both resting and glucan-activated hMDM were used in the experiments described below, yielding identical results. It was found that the uptake of apoptotic PMN was stimulated in a time- and concentration-dependent manner by pretreatment with RgpB (Figure 2a). After $1 \mathrm{~h}$ of preincubation, a significant stimulatory effect was observed at a concentration of $\mathrm{RgpB} \geqslant 30 \mathrm{~nm}$, but was maximal when apoptotic PMNs were exposed to $300 \mathrm{~nm}$ RgpB. At the later concentration, the intensity of phagocytosis reached a plateau at a level twofold higher than the uptake of control, nontreated cells. It is remarkable that fresh PMNs, which normally are not recognized as a target for ingestion by macrophages, become rapidly phagocytosed after being exposed to RgpB (Figure 2b). In parallel to the engulfment of apoptotic cells, the uptake of fresh PMNs was induced by RgpB in a similar time- and concentration-dependent manner. In this case, however, the effect was significant only at 100 and $300 \mathrm{~nm}$ enzyme concentration (Figure 2b). After $1 \mathrm{~h}$ preincubation with $300 \mathrm{~nm}$ RgpB, the uptake level of fresh PMN by macrophages was comparable to the intensity of phagocytosis observed for apoptotic cells.

As our NE activity-based method, like the classical method of MPO staining, cannot distinguish well between bound and ingested cells, we have applied flow cytometry analysis to confirm that RgpB treatment of viable fresh PMN promotes their phagocytosis by macrophages. Fluorescently stained, both fresh and apoptotic PMN, treated or untreated with gingipains were cocultured with adherent macrophages and nonengulfed cells removed by washing. Macrophages were detached by trypsinization and subjected to flow cytometric analysis. As clearly shown in Figure 2c, RgpB treatment of viable PMNs provoked their uptake by hMDM which is in stark contrast to nontreated PMNs. Also, in corroboration with the NE-activity-based assay, preincubation of apoptotic PMNs with RgpB significantly enhanced their uptake by macrophages (Figure 2d and Supplementary Figure S1).

The final proof that RgpB treatment promotes phagocytosis of fresh viable PMN was provided by transmission electron microscopy (TEM) and confocal microscopic analysis of macrophages fed with fluorescently labeled neutrophils. A representative set of TEM images showing hMDMs engorged with healthy-looking PMNs is presented in Figure 3. The fact that RgpB-treated PMN are ingested by macrophages is further supported by confocal images presented in the supplement. Very few if any fresh, control PMN were engulfed by hMDM but after RgpB pretreatment, most macrophages harbor at least one neutrophil intracellularly (Supplementary Figures S2 and S3). Only occasionally, a surface-bound neutrophil was observed; arguing against possibility that gingipain treatment induces only adherence of PMN to hMDM without engulfment. Significantly, ingested gingipain-treated PMNs have clearly different morphology than the ingested, control apoptotic cells (Supplementary Figure S2bc). Furthermore, prolonged cultivation of hMDMs with engulfed fresh $\mathrm{PMNs}$ resulted in PMNs digestion into an amorphous material with no resemblance to apoptotic bodies, thus providing further proof of their localization within phagolysosomes (Supplementary Figure S3).

The other Arg-specific gingipain produced by $P$. gingivalis, HRgpA, was also shown to efficiently stimulate uptake of apoptotic PMNs and induce engulfment of fresh PMNs, both to the same level as RgpB (Figure 2e). However, in contrast to Rgps, pretreatment of PMN with Kgp, the lysine-specific protease, did not have any significant effect on the ingestion of these cells by macrophages. This observation suggests that stimulation of phagocytosis by Rgps is dependent on the proteolytic activity and specificity of the gingipains. This assumption was confirmed by exposure of PMN, both fresh and apoptotic, to $300 \mathrm{~nm}$ of active, non activated (in the absence of reducing agent), or specific inhibitor pretreated RgpB and HRgpA. The results from this experiment clearly indicate that the effect of HRgpA and RgpB on phagocytosis of both apoptotic (data not shown) and fresh PMN (Figure 2f) is dependent on the proteolytic activity of these gingipains. The same observation was apparent from flow cytometry analysis of the phagocytosis of fluorescently labeled PMNs treated with active and inactive protease (data not shown)

There are two alternatives as to how Rgps can exert their effect. They can either proteolytically modify the PMN cell surface or act intracellularly after being internalized. To distinguish between these two vastly distinct modes of action, we determined the recovery of active RgpB after $1 \mathrm{~h}$ incubation with both fresh and apoptotic suspensions of PMN. In both cases, RgpB was quantitatively recovered in supernatants from the suspension after PMN were removed by centrifugation (data not shown). This result argues in favor of the fact that gingipains act on the PMN cell surface. 

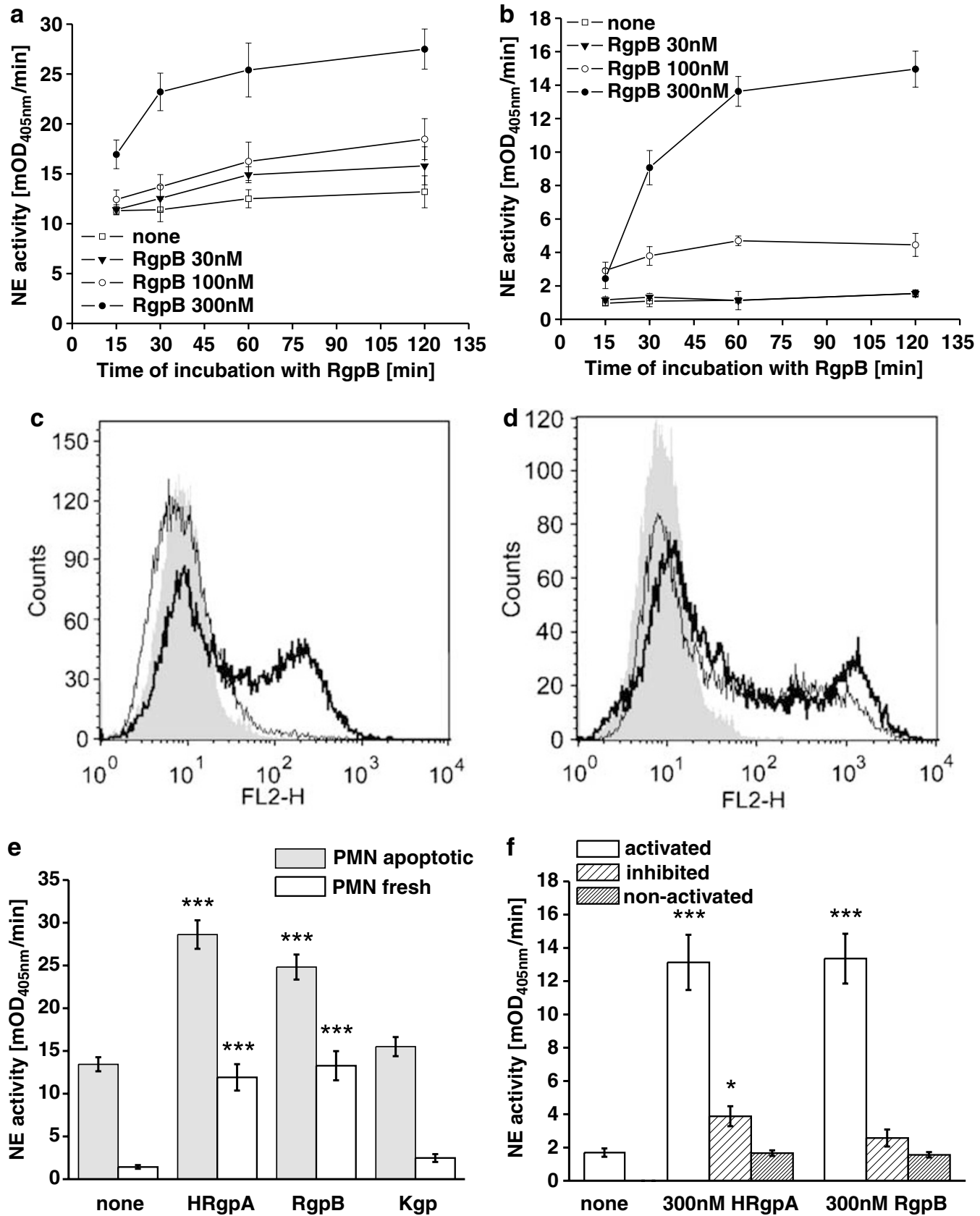

Figure 2 Exposure of PMNs to gingipains stimulates clearance of apoptotic cells and induces uptake of fresh PMNs by macrophages in a proteolysis-dependent manner. Apoptotic (a) or fresh (b) PMNs were treated with indicated concentrations of RgpB for up to $120 \mathrm{~min}$ at $37^{\circ} \mathrm{C}$ in the presence of $5 \%$ human serum. Cells were washed with fresh medium to remove gingipains before being added to macrophages cultures at $2 \times 10^{6}$ cells/well (PMN : hMDM ratio $=20: 1$ ) of 24 -well plate in media with $10 \%$ human serum. After $2 \mathrm{~h}$ of incubation at $37^{\circ} \mathrm{C}$, cell lysates were assayed for NE activity as described in Materials and Methods. The effect of RgpB on promoting/stimulating uptake was analyzed by flow cytometry using fluorescently labeled (with PKH26) fresh (c) and apoptotic (d) PMNs preincubated with $300 \mathrm{~nm} \mathrm{RgpB} \mathrm{(thick} \mathrm{line)} \mathrm{or} \mathrm{with} \mathrm{the} \mathrm{vehicle} \mathrm{alone}$ (thin line). The gray area represents the macrophage control. To compare the effect of HRgpA and Kgp to that of RgpB on PMN phagocytosis (e) and establish the dependence of gingipains action on their proteolytic activity (f), fresh or apoptotic cells were treated with each proteinase at $300 \mathrm{~nm}$ for $1 \mathrm{~h}$ and processed as described above. For the proteolytic-activity dependence assay, $\mathrm{HRgpA}$ and $\mathrm{RgpB}$ were used in either their active form, nonactivated or pretreated with specific inhibitors. Data are mean \pm S.D. from three independent experiments, each performed in triplicate: ${ }^{*} P<0.05 ;{ }^{\star \star} P<0.01 ;{ }^{* \star \star} P<0.001$ significance as compared to untreated controls

Treatment with gingipains does not induce apoptosis of PMNs. A distinctive and early feature of cell apoptosis is the exposure of PS on the outer leaflet of the plasma membrane, ${ }^{31}$ which constitutes an 'eat-me' signal for neighboring phagocytes. In this context, gingipain-induced apoptosis of fresh PMN, and the subsequent surface PS exposure may explain the observed induction and enhancement of recognition and clearance of these cells by macrophages. Therefore, we have carefully studied the PS exposure on fresh and apoptotic PMNs after gingipain 

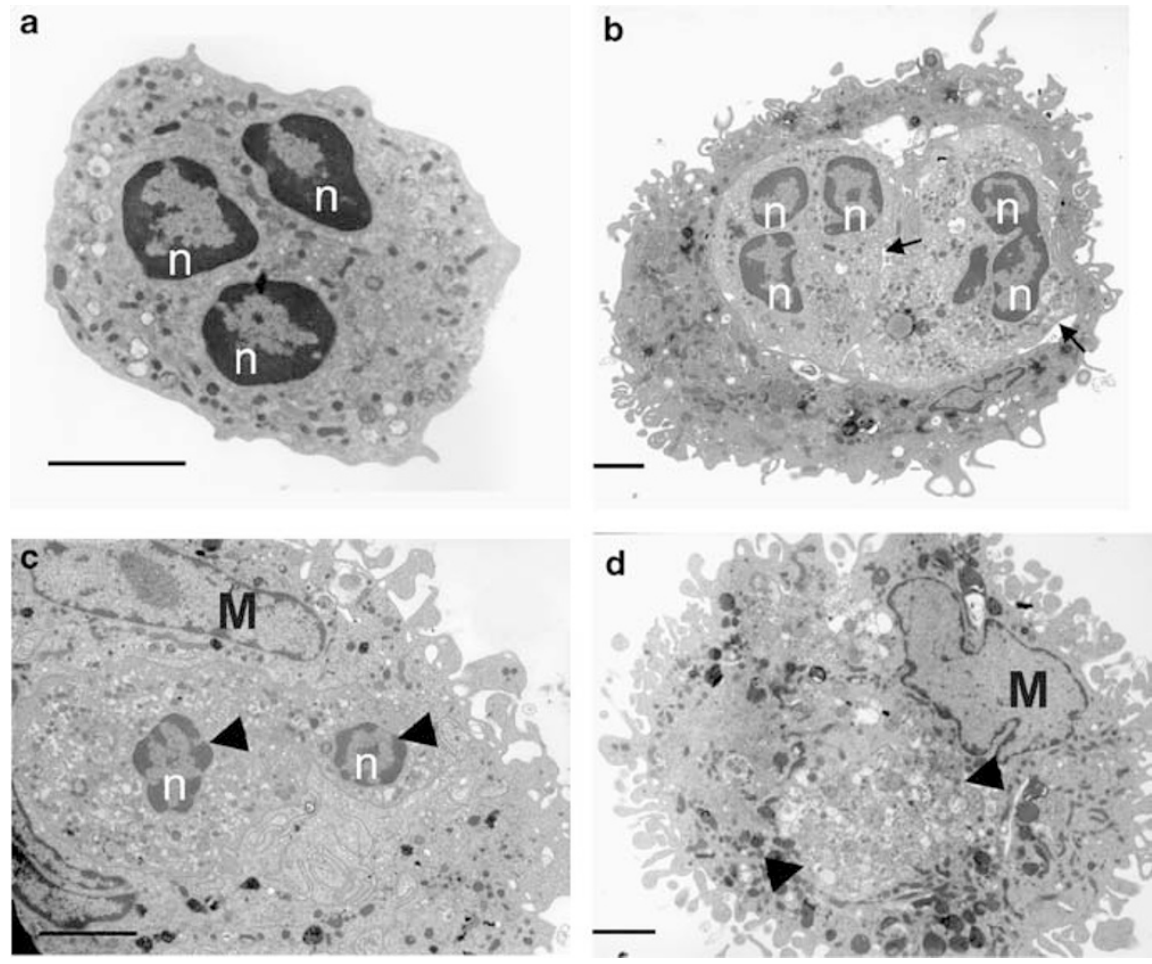

Figure 3 Ultrastructural (TEM) analysis of different stages of phagocytosis of healthy RgpB-treated PMNs by macrophages (hMDMs). Individual panels show (a) freshly isolated, RgpB-treated PMN with characteristic segmented nucleus ( $\mathrm{n}$ ) and variety of cytoplasmic granules; (b) two PMNs engulfed within the phagocytic cup, arrows pointing at the PMN intact cell membrane; (c) fully engulfed PMN, black arrowheads indicate the intact nuclear membrane; (d) digested PMN within a macrophage, arrowheads point at remnants of PMNs. M, the macrophage nuclei. Scale bars represent $2 \mu \mathrm{m}$

treatment. The level of PS on the PMN surface was evaluated by staining with FITC-conjugated Annexin $\mathrm{V}$ followed by flow cytometry analysis. The treatment of fresh PMNs with $300 \mathrm{~nm} \mathrm{HRgpA,} \mathrm{RgpB,} \mathrm{or} \mathrm{Kgp} \mathrm{for} 1 \mathrm{~h}$ did not affect binding of Annexin $\mathrm{V}$, which remained at the same level as in nontreated PMNs (Figure 4a). In addition, gingipains treatment was without any deleterious effect on the viability of PMNs, as clearly indicated by a propidium iodide (PI) exclusion test (Figure 4a). The same observation was made after treatment of spontaneously apoptotic PMNs with gingipains (Figure 4b). In light of these results, it is evident that the treatment of PMN with gingipains does not affect PS distribution at the cell surface and has no cytotoxic effect on PMNs.

To rule out the possibility that gingipains may affect the later stages of spontaneously occurring apoptosis, we have also analyzed and compared DNA integrity of the RgpB-treated and untreated PMNs. For this purpose, both fresh and apoptotic PMNs, treated with RgpB or not (control cells) were labeled for DNA nicks using the terminal dUTP nick end labeling (TUNEL) kit and subjected to flow cytometry analysis. In addition, total DNA was isolated $24 \mathrm{~h}$ after exposure of fresh or apoptotic PMNs to RgpB and electrophoretically analyzed. As presented in Figure 4c, there were no DNA nicks in fresh PMN treated with gingipains (TUNEL-negative) and gingipain treatment did not affect the TUNEL positivity of apoptotic PMNs (Figure 4d). In corroboration with the flow cytometry analysis, viable gingipain-treated PMNs were also TUNEL negative in fluorescence microscopy (data not shown).
Finally, in accordance with the TUNEL data, treatment with $\mathrm{RgpB}$ had no effect on the process of DNA fragmentation (Figure 4e).

Cumulatively, these data strongly argue that gingipain stimulation of apoptotic PMN clearance and induction of uptake of fresh PMN is unrelated to typical changes associated with apoptosis, especially general PS redistribution to the cell surface.

Stimulation/induction of PMN clearance by macrophages is unique for gingipains $R$ and their related homolog. In order to determine whether the effect of induction and/or upregulation of phagocytosis of PMNs can be exerted by other proteinases, especially serine proteinases released from activated PMNs, both fresh and apoptotic PMNs were pretreated with several enzymes including elastase, CG, trypsin, thrombin and clostripain, washed, and fed to macrophages. Both resting and glucanstimulated hMDM were used in these experiments, yielding similar results. To avoid a proteinase-quenching effect owing to the presence of inhibitors in human serum, these experiments were performed in media supplemented with bovine serum albumin (BSA). Except for clostripain (Figure 5a), none of the tested proteinases were able to enhance PMN uptake by macrophages. Indeed, CG in a concentration-dependent manner (Figure $5 \mathrm{~b}$ ) and to a lesser extent, thrombin and trypsin (Figure 5c) significantly depressed phagocytosis of apoptotic PMN by hMDM. None 

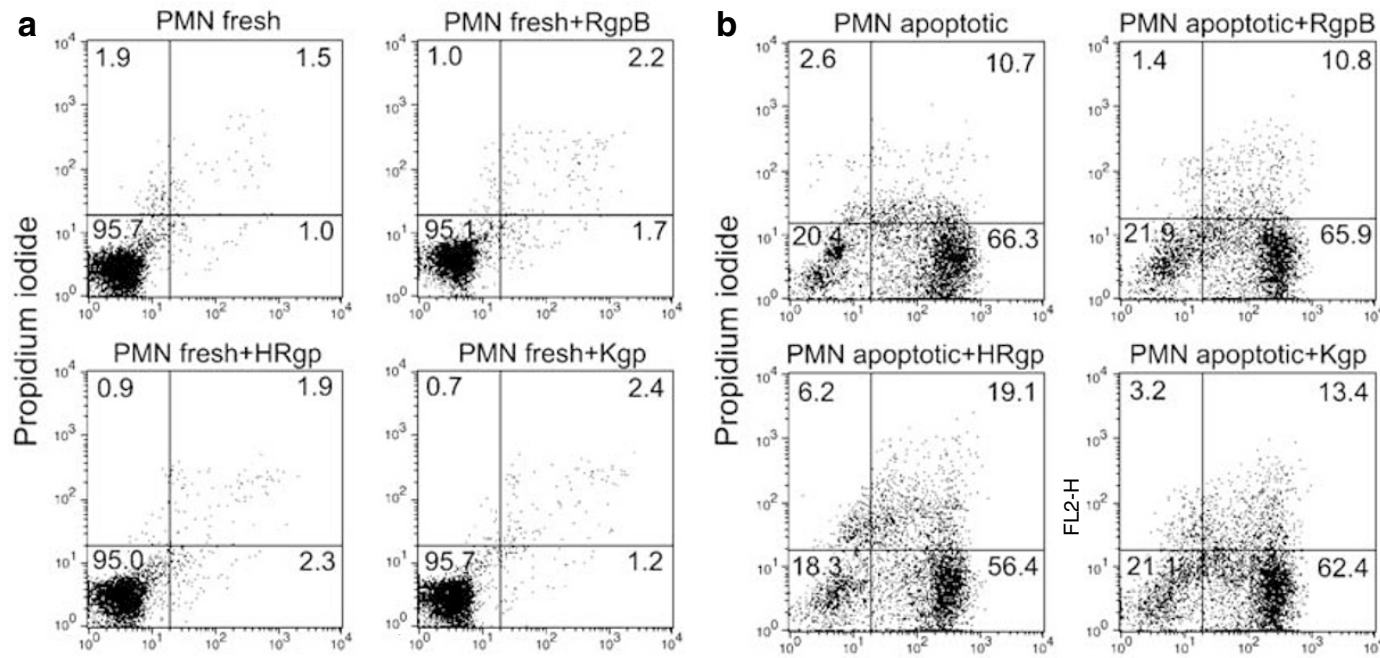

Annexin V - FITC

Annexin V - FITC
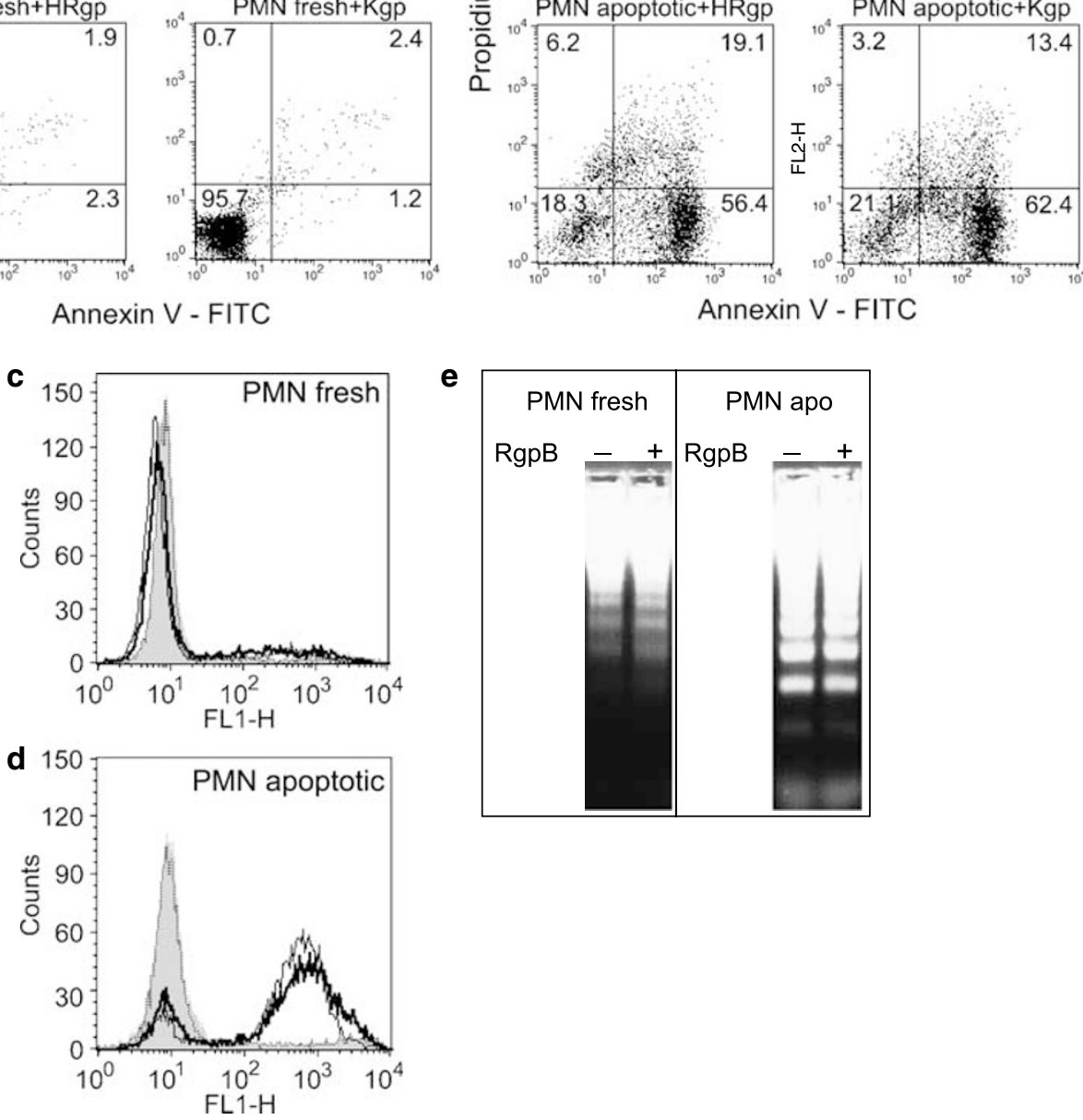
nase which is structurally and functionally related to Rgps. ${ }^{33}$ This proteinase was able to induce the phagocytosis of fresh PMNs and stimulated clearance of apoptotic PMNs to the same level as RgpB. As in the case of Rgps, the effect was dependent on enzyme activity and nonactivated clostripain did not alter PMN clearance (Figure 5a). As all these comparative experiments were performed in the absence of human serum, it is important to note that the observed effects on PMN clearance by gingipains, clostripain, and serine proteases do not depend on proteolysis or cobinding of some human serum constituents but are exerted by direct proteolytic modification of PMN surface proteins.

Both CG and RgpB cleave CD31, but while gingipain generates an 'eat-me' signal, CG destroys it. It was shown that CD31 acts as an antiphagocytic signal, which protects healthy cells from being accidentally engulfed by phagocytes. ${ }^{34}$ Therefore, we assumed that the cleavage of CD31 by RgpB may be responsible for enhanced clearance of PMNs. Indeed, this molecule was efficiently cleaved in a time- and concentration-dependent manner from both healthy (Figure $6 a$ and b) and apoptotic cells (data not shown) by RgpB, and even more efficiently by CG (Figure 6c and $\mathrm{d}$ ). Western blot analysis of the concentrated growth media could not detect the accumulation of released CD31 (data not shown), indicating that the receptor was proteolytically degraded by both RgpB and CG either on the cell surface and/or after being released into the medium. Paradoxically, however, preincubation of apoptotic PMNs with CG almost totally abolished their clearance by macrophages (Figure $5 \mathrm{~b}$ ). To eliminate the possibility that the effect was exerted through the cleavage of a macrophage
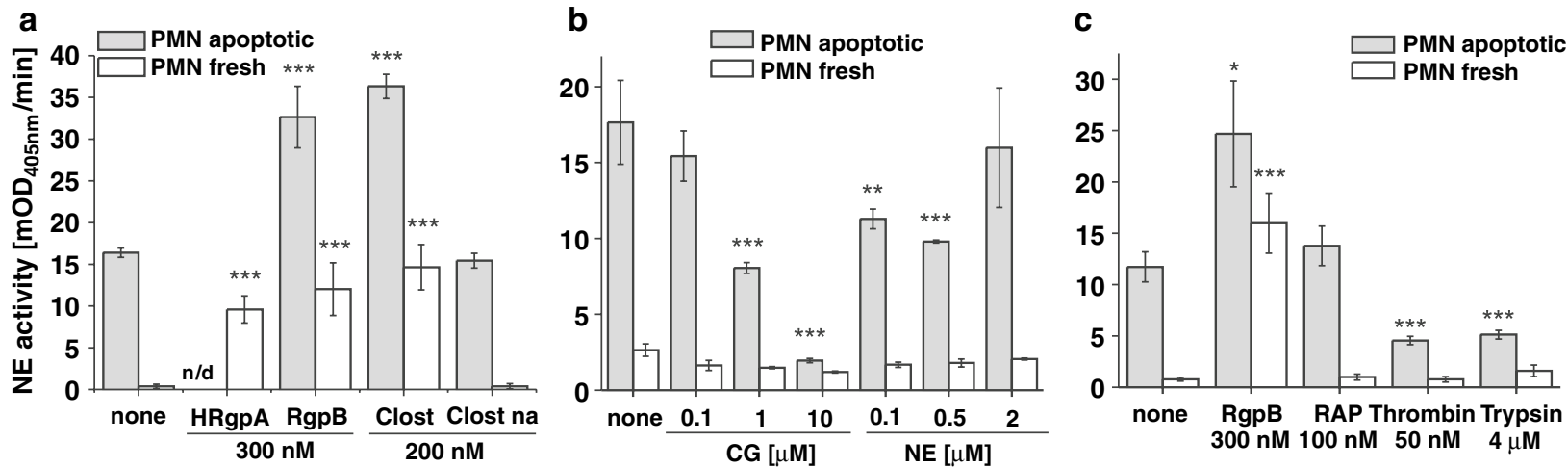

Figure 5 The effects of serine proteinases and clostripain on PMN uptake by macrophages. Apoptotic (gray bars) or fresh (open bars) PMNs were pretreated with HRgpA, $\mathrm{RgpB}$, and clostripain (a); CG or NE, (b); RgpB, PAR-2 agonist peptide (RAP), thrombin, and trypsin, (c); at concentrations indicated in the figure for $1 \mathrm{~h}$ at $37^{\circ} \mathrm{C}$ in the presence of $0.5 \% \mathrm{BSA}$. Cells were washed with culture medium at $4^{\circ} \mathrm{C}$ to remove proteinases before being added to macrophage cultures at $2 \times 10^{6} \mathrm{cells} / \mathrm{well}(\mathrm{PMN}: \mathrm{hMDM}$ ratio $=20: 1$ ) of a 24-well plate in medium with $10 \%$ human serum and incubated for $2 \mathrm{~h}$ at $37^{\circ} \mathrm{C}$. NE activity was measured in cell lysates as described in Materials and Methods. Clost, active clostripain; Clost na, nonactivated clostripain. Data are the mean \pm S.D. from two independent experiments, each performed in triplicate: ${ }^{*} P<0.05$; ${ }^{\star \star} P<0.01 ;{ }^{\star \star *} P<0.001$ significance as compared to untreated controls
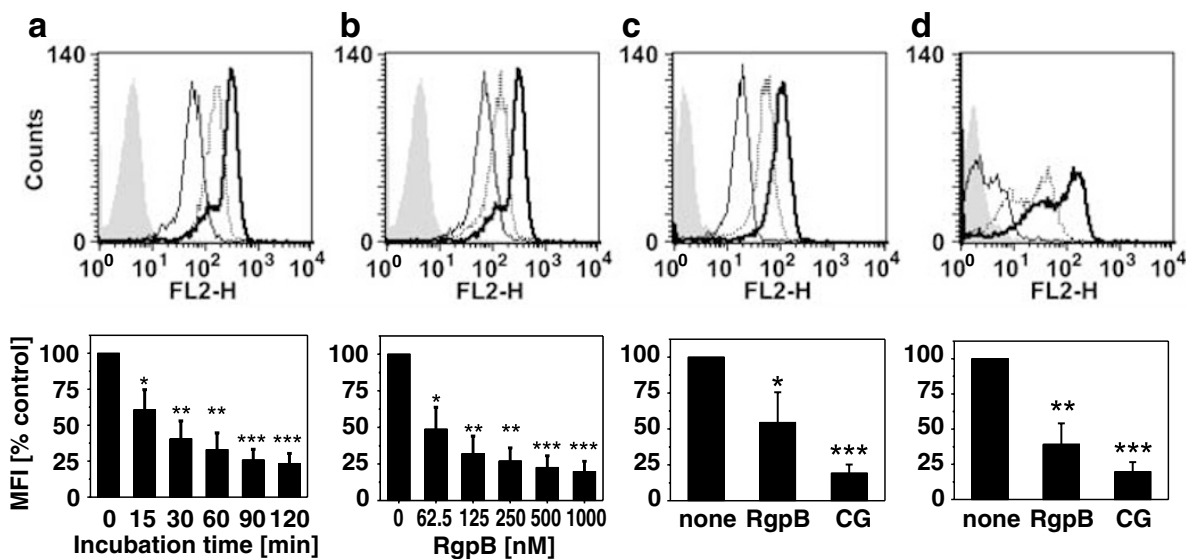

Figure 6 Cleavage of surface CD31 (PECAM) on fresh and apoptotic PMNs by RgpB or CG. Fresh (a, b, and $\mathbf{c}$ ) and apoptotic (d) PMNs were incubated alone (thick line) or with RgpB at $250 \mathrm{~nm}$ in a time-dependent manner (a) for $15 \mathrm{~min}$ (dotted line) or $120 \mathrm{~min}$ (thin line), or in a concentration-dependent manner (b) for $120 \mathrm{~min}$ with $62.5 \mathrm{nM}$ (dotted line) or $250 \mathrm{~nm}$ (thin line) RgpB. Panels c and d: PMN were incubated with $250 \mathrm{~nm} \mathrm{RgpB} \mathrm{(dotted} \mathrm{line)} \mathrm{or} 5 \mu \mathrm{M} \mathrm{CG}$ (thin line) for 120 min. The level of CD31 was analyzed by flow cytometry using fluorescein-labeled anti-CD31 mAb, gray area represents the isotypic control for nontreated cells which was not affected by protease treatment. In addition to BSA and FBS, human serum, both autologous and mixed from five heterologous donors, were used as blocking reagents yielding virtually identical CD31 staining pattern. Histograms show quantified data $( \pm$ S.D. $)$ of four independent experiments, each performed in duplicate, of CD31 shedding expressed as percent of mean fluorescence intensity of control cells: ${ }^{\star} P<0.05 ;{ }^{\star \star} P<0.01$; ${ }^{\star \star \star} P<0.001$ significance as compared to untreated controls 
receptor involved in clearance by $\mathrm{CG}$ associated with the PMN surface, ${ }^{35,36}$ CG-treated PMNs were incubated with Suc-Ala-Pro-Phe-cmk, a potent CG inhibitor, before being cocultured with macrophages. Such treatment did not improve engulfment of CG-treated PMNs indicating that the enzyme apparently proteolytically inactivates an 'eat-me' signal(s) on the cell surface of PMNs (data not shown).

To investigate the susceptibility of the 'eat-me' signal to proteolytic degradation by CG, both fresh and apoptotic PMNs after being treated with RgpB were preincubated with $C G$ and then fed to macrophages. In both cases, such sequential treatment abolished the ingestion of PMNs by macrophages. The same effect was observed when PMNs were treated in the reverse order, first with CG followed by RgpB (Figure 7). These results argue that CG destroys not only the 'native' and the gingipain-generated 'eat-me' signals, but it also degrades the unknown precursor to the gingipain-processed 'eat-me' signal on fresh PMN. Furthermore, our data clearly indicate that although CG and RgpB shed CD31 from the PMN surface with similar efficiency, this proteolytic event alone is not sufficient to trigger PMN engulfment by macrophage. Apparently, the effective cell ingestion requires expression of the 'eat-me signal' which is generated by RgpB but destroyed by CG.

\section{Uptake of RgpB-treated PMN by hMDM is independent of several receptors but is blocked by PS liposomes.} Several different receptors on macrophages have been implicated in the recognition and/or uptake of apoptotic cells. To test the possibility that one of these pathways is involved in the engulfment of RgpB-treated PMN, hMDM monolayers were preincubated with and PMN phagocytosis performed in the presence of ligands known to block uptake

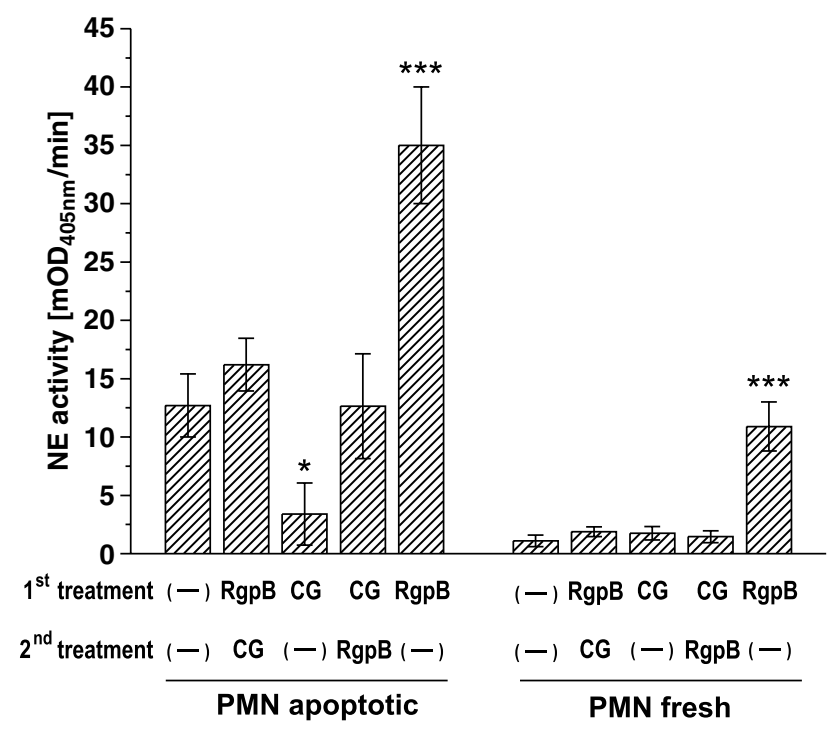

Figure 7 CG downregulates RgpB-induced phagocytosis of fresh and apoptotic PMNs. PMN were preincubated first with one protease, washed then incubated with the second enzyme (each incubation is for 75 min with either $300 \mathrm{~nm} \mathrm{RgpB}$ or $5 \mu \mathrm{M}$ CG) before PMN uptake by hMDM was determined. Data are the mean \pm S.D. from two independent experiments, each performed in triplicate: ${ }^{\star} P<0.05$; ${ }^{\star \star \star} P<0.001$ significance as compared to untreated controls of apoptotic cells by macrophages (Figure 8). Interestingly, none of the neutralizing mAbs specific for CD14, CD36, ICAM-3, TSP, or calreticulin (CRT) nor inhibitory soluble ligands such as RGDS peptide and methylamine-treated $\alpha_{2} M$ (for vitronectin receptor $\left(\alpha_{v} \beta_{3}\right)$ and CD91, respectively), affected the uptake of RgpB-treated PMN by hMDM. Consistent with the lack of effect of methylamine-treated $\alpha_{2} \mathrm{M}$, the presence of the soluble receptor of this protein (sCD91) was also unable to inhibit PMN phagocytosis. Similarly, neither RgpB nor CG treatment changed the level of the Annexin I on PMN (data not shown) arguing against the possibility that these proteases affected Annexin Idependent pathway of apoptotic cell clearance. ${ }^{37}$

Interestingly, among all investigated compounds only PS, but not phosphatidylcholine (PC) abolished uptake of both fresh and apoptotic PMN pretreated with RgpB (Figure 8). This was an unexpected finding as PS is absent from the surface of fresh, healthy PMN preincubated with RgpB (Figure 4a).

Phagocytosis of gingipain-treated PMNs is nonphlogistic. Several reports have indicated that uptake of apoptotic cells change the macrophage phenotype from proto anti-inflammatory (extensively reviewed by Savill et al. ${ }^{4}$ and Gregory and Devitt ${ }^{38}$ ). Therefore, it was important to test the response of hMDM to contact with gingipain-treated PMNs. As expected, phagocytosis of apoptotic PMNs, both control or gingipain-treated, decreased TNF- $\alpha$ secretion by LPS-stimulated macrophages (Figure 9). Significantly, fresh

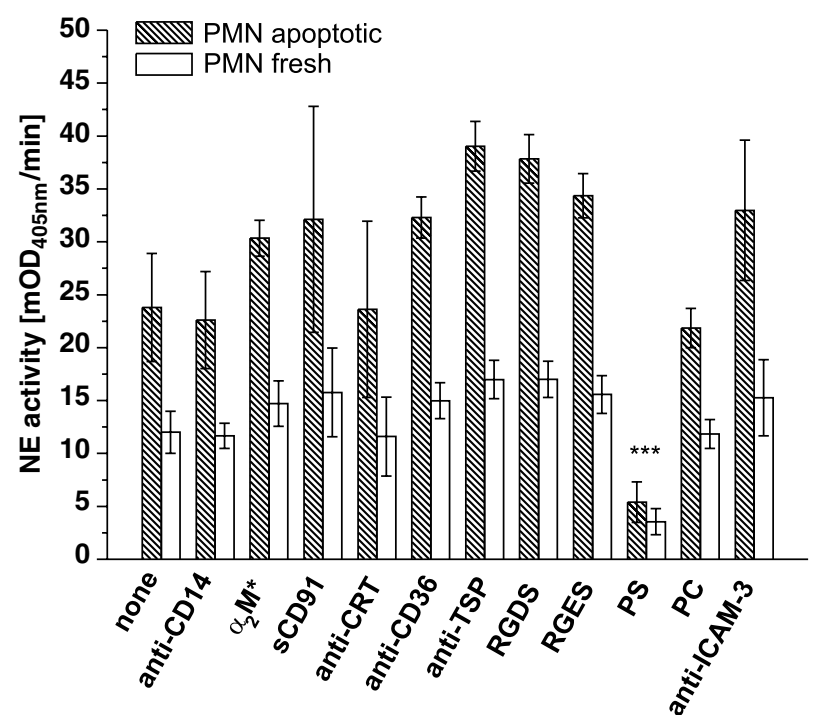

Figure 8 Phagocytosis of RgpB-treated PMNs by hMDMs is effectively blocked only by PS-containing liposomes. hMDMs were preincubated with compounds known to block apoptotic cell clearance, including methylamine-treated $\alpha_{2}$ macroglobulin $\left(\alpha_{2} \mathrm{M}^{*}\right)$, RGDS peptide and PS, and mAbs specific for CD14, ICAM-3, CRT, CD36, TSP. Conversely, RgpB-treated PMNs were preincubated with the soluble CD91 receptor (SCD91). Incubation with the RGES peptide and PC were used as controls since neither compound affects phagocytosis of apoptotic cells. After preincubation with the inhibiting ligand, PMNs were added to hMDM culture and their uptake determined using the NE activity assay. Data are mean \pm S.D. from three independent experiments, each performed in triplicate: ${ }^{* \star *} P<0.001$ significance as compared to untreated controls 


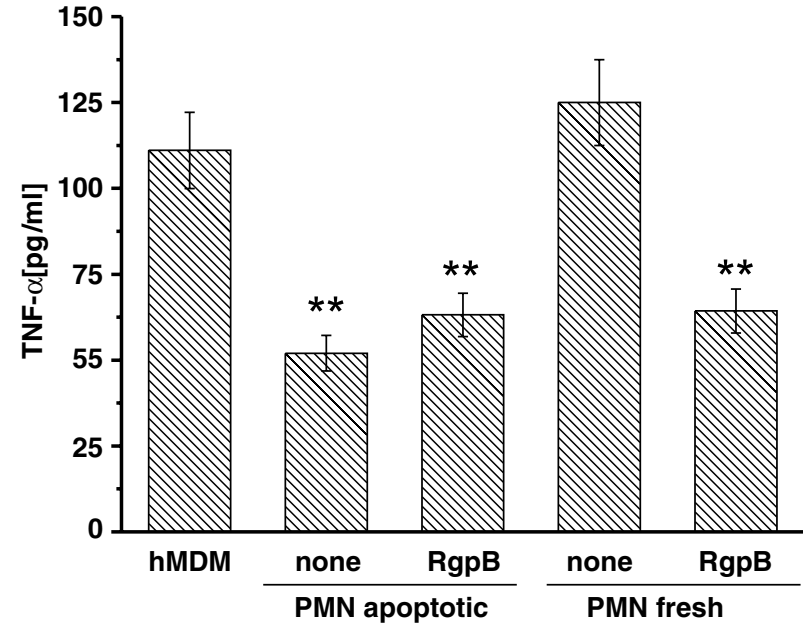

Figure 9 Ingestion of RgpB-treated PMNs by hMDM suppresses LPS-induced TNF- $\alpha$ production. Macrophages were allowed to phagocytose treated and untreated PMNs for $2 \mathrm{~h}$ and after noningested cells were washed out, macrophages were stimulated with LPS for $18 \mathrm{~h}$. Culture supernatants were collected and TNF- $\alpha$ concentration was determined by ELISA. Data are the mean \pm S.D. from three independent experiments, each performed in duplicate: ${ }^{* *} P<0.01$ significance as compared to untreated controls

PMNs preincubated with RgpB also suppressed LPSinduced TNF- $\alpha$ release by hMDM to the level exerted by phagocytosis of apoptotic PMNs, whereas nontreated healthy PMN gave no such effect (Figure 9). Without LPS stimulation, preincubation of hMDM with PMNs, fresh or apoptotic, treated or untreated with $\mathrm{RgpB}$ did not result in any significant TNF- $\alpha$ production (data not shown).

\section{Discussion}

Here, we demonstrated that PS is not absolutely required for the uptake of PMNs by hMDM. First, preincubation of apoptotic PMNs with CG totally abolished their clearance without affecting the level of PS exposure on the cell surface. Second, fresh, healthy PMNs exposed to bacteria-derived proteases were sensitized for very efficient uptake despite no significant exposure of PS on the cell surface or induction of necrotic change. In both cases, the effect was entirely dependent on proteolytic activity arguing for proteolytic modification of surface molecules, but while Rgps and clostripain generated an 'eat-me' signal, CG destroyed it. The vastly divergent effect of CG and Rgp treatments could be due to the differences in substrate specificity for each enzyme: CG prefers to cleave after bulky hydrophobic residues, whereas Rgps cleave exclusively at the carbonyl side of arginine. The availability of these residues in vulnerable sites on a protein will dictate whether these enzymes can cleave the protein and modify its behavior. Therefore, it seems apparent that the 'eat-me' ligand(s) generated on enzyme-treated PMNs is a protein recognized by a receptor(s) both on resting and glucan-stimulated hMDMs. The identity of this ligand(s) remains to be elucidated, but it is clear that it is not ICAM- $3^{39}$ or Annexin I, ${ }^{37}$ which have both been implicated in apoptotic cell clearance. Moreover, the classical inhibitory study of apoptotic cell engulfment by phagocytes using a panel of blocking antibodies and ligands strongly indicated that a gingipain-generated ligand was not recognized by CD14, CD91, or components of the $\alpha_{v} \beta_{3} /$ CD36/TSP complex. The involvement of other bridging molecules, including serum proteins and macrophage-derived opsonins or proteolytically modified serum components in generation of the 'eat-me' signal by gingipains can be excluded as soluble opsonins are removed by hMDM culture medium replacement with the PMN suspension and the same results were obtained in both the presence and absence of serum. The relation of this novel ligand to molecules exposed on the surface of spontaneously apoptotic PMNs needs to be elucidated. Collectively, the presented data indicate that the 'tether and tickle' mechanism, ${ }^{3}$ in which PS triggers macrophage to ingest apoptotic cells tethered by other receptor-ligand interactions is not an exclusive pathway of the clearance of dying PMNs by hMDM.

The other key consequence of phagocytosis of apoptotic cells by macrophages is the suppression of production of inflammatory mediators, both in vitro and in vivo. ${ }^{40-42}$ Also in this process, the interaction between PS and its specific receptor on macrophage is suggested to be a prerequisite for stimulation of the anti-inflammatory response. Again, our data argue against the fact that PS exposure on the external cell membrane is a critical structure required for apoptotic PMNs to quench the production of TNF- $\alpha$ by LPS-stimulated hMDM. Ingestion of gingipain-treated healthy PMNs without PS on the cell surface had the same anti-inflammatory effect as phagocytosis of apoptotic cells. In total, these results indicated that the most likely signal to switch off the proinflammatory cytokine production may be delivered by interaction of a protein ligand(s) with a receptor(s) on the phagocyte. This suggestion has support from observations that the ligation of the CD36 receptors in monocytes caused reduction in TNF- $\alpha$ and a simultaneous increase in IL-10 production. ${ }^{40}$

The PS-independent clearance of apoptotic PMN is surprising in the light of the fact that among several compounds known to interfere with uptake of apoptotic cells, only PS liposomes are capable of inhibiting ingestion of RgpBtreated PMN. A plausible rationalization of this ambiguity may rely on the assumption that PS liposomes inhibit the classic mechanism involving PS, in which PS is exposed in the engulfment synapse in response to RgpB-treated PMN to physical contact with the macrophage. However, a detailed investigation of membrane dynamics in the engulfment process is beyond the scope of this paper. On the other hand, the apparent contradiction could be explained by PS liposomes binding to a receptor(s) specifically recognizing the novel, protease-sensitive 'eat-me' ligand on the PMN surface. Liposome association with a receptor(s) apparently hinders the interaction between the receptor and the proteinaceous ligand. Indeed, several apoptotic cell clearance receptors, including the $\alpha_{2} \mathrm{M}^{*} / L D L-$-receptor (CD91), scavenger receptors (CD36), and PS-R directly recognize PS on apoptotic cells. One or more of these receptors may interact with the novel proteinaceous ligand. This molecular event alone is apparently sufficient to tether PMN to macrophages and not only trigger PMN cell uptake but also anti-inflammatory signaling. The relationship between the novel protease-sensitive ligand(s) to ligand(s) expressed during apoptosis is unknown 
but the sensitivity of the latter to CG inactivation indicates its proteinaceous nature.

In many regards, the proteinaceous ligand-dependent clearance of PMNs described here differs considerably from clearance of other apoptotic cells in which a different receptor-ligand interaction is required for the different phases of clearance. Moreover, in the case of other cells, the PSPS-R ligation is the key event in phagocytic and antiinflammatory signaling. It can be argued that as PMNs are loaded with proteolytic enzymes that are capable of causing liquefaction of the soft tissue, a special, nonredundant pathway of clearance has been developed to effectively clear aging PMNs before the cell membrane integrity is compromised and the damaging proteases are released. In humans, under physiological conditions such a mechanism in conjunction with other pathways of clearance acts to remove $10^{11}$ PMNs daily.

The failure of apoptotic cell clearance has daring consequences including the development of systemic autoimmune diseases, specifically, failure to remove PMN nonphlogistically may contribute and/or aggravate chronic inflammatory diseases such as rheumatoid arthritis, non-CF bronchiaectasis, and cystic fibrosis. In lung diseases, apoptotic PMN accumulation is suggested to be owing to elastase and $C G$ interference with phagocytosis of apoptotic cells by alveolar macrophages. The mechanism by which CG hinders apoptotic PMNs uptake is unknown but it has been shown that the elastase effect is exerted by shedding of PS-R. ${ }^{43}$ However, our data strongly suggest that degradation of the 'eat-me' signal on apoptotic PMNs by CG may also significantly contribute to retention of apoptotic cells in the lungs. Furthermore, a similar scenario can be envisioned in periodontitis. At this location, the situation is additionally complicated by tagging of healthy PMNs for clearance through cleavage of the repelling signals provided by CD31 and the generation of a novel 'eat-me' signal by the exogenously derived gingipains. This may lead to decrease in numbers of functional PMNs and facilitate the site colonization by $P$. gingivalis. However, once the milieu gets saturated with proteinases released from PMNs, the PS-Rdependent and -independent pathways of quenching inflammation are unlikely to be operative and inefficiently cleared apoptotic cells would be subject to secondary necrosis, thereby, further fueling persistent inflammation: a hallmark of chronic periodontitis. This scenario fits very well into the clinical picture of adult onset of periodontal disease where high levels of proteolytic activity, both PMN and $P$. gingivalis derived, are present in the gingival exudates together with large numbers of necrotic PMNs. ${ }^{11,15,44}$ Thus, periodontitis can be considered as another example of inflammatory disease caused by proteinase-induced dysfunctional clearance of apoptotic cells.

\footnotetext{
Materials and Methods

Cells. hMDM were obtained from peripheral blood mononuclear cells (PBMCs). Briefly, PBMCs were isolated from human blood using a Ficoll-Paque (Pharmacia, Uppsala, Sweden) density gradient and plated at $3 \times 10^{6} /$ well in 24-well plates (Sarstedt, Newton, NC, USA) or Primaria ${ }^{\mathrm{TM}}$ 24-well plates (Becton Dickinson, Franklin Lakes, NJ, USA) in RPMl1640 (Gibco) supplemented with $2 \mathrm{mM}$ L-glutamine, $50 \mu \mathrm{g} / \mathrm{ml}$ gentamycin (Sigma), and $10 \%$ pooled heat-inactivated
}

human $A B$ serum. After $24 \mathrm{~h}$, non-adherent PBMCs were removed by washing with complete medium, and adherent cells were cultured in this medium for 7 days with fresh medium changed every 2 days. For some experiments, MDMs were stimulated with $25 \mu \mathrm{g} / \mathrm{ml} \beta$-1,3-glucan (Sigma) suspended in culture medium. After $48 \mathrm{~h}$, the MDMs were washed twice with RPMI to remove noningested particles before PMNs were added for phagocytosis. For confocal microscopy analysis, macrophages were cultured on glass coverslips in 6-well culture plates (Sarstedt, Newton, NC, USA).

PMN cells were isolated from erythrosediments by sedimentation of red cells in $1 \%$ polyvinylalcohol solution (Merck, Hohenbrunn, Germany) for $20 \mathrm{~min}$ at room temperature. PMNs were collected from the upper layer and contaminated erythrocytes lysed with distilled water for $20 \mathrm{~s}$. Pappenheim-staining indicated that cells isolated in this way were at least $90 \%$ homogenous. PMN were used immediately after harvest (fresh, non-apoptotic) or after incubation for $24 \mathrm{~h}$ in RPMl1640 supplemented with L-glutamine (2 mM), gentamycin (50 $\mu \mathrm{g} / \mathrm{ml})$, and $5 \%$ heat-inactivated FCS (Gibco) in a humidified atmosphere containing $5 \% \mathrm{CO}_{2}$ at $37^{\circ} \mathrm{C}$ (aged, apoptotic). The percentage of Annexin V-positive and PI-negative cells in populations of fresh and aged PMN ranged from 1 to $7 \%$ and 45 to $78 \%$, respectively, and the proportion of PI-positive cells did not exceed $15 \%$.

Detection of apoptosis. Externalization of anionic phospholipid PS, an early occurring feature of apoptosis, ${ }^{31}$ was assessed by the binding of FITC-labeled Annexin $\mathrm{V}$ and exclusion of $\mathrm{PI}$, according to the manufacturer's recommendations (Annexin V-FITC kit, Bender MedSystems, Vienna, Austria), followed by analysis with a FACScan flow cytometer (Becton Dickinson). Additionally, cellular morphology was evaluated for features of apoptosis using bright-field phase contrast microscopy. To detect the early stage of DNA fragmentation, labeling of DNA strand breaks with terminal transferase (TUNEL) were performed. The staining procedure was carried out according to the manufacturer's recommendations (In situ Cell Death Detection Kit, Roche), followed by analysis with a FACScan flow cytometer (Becton Dickinson). As a negative control, cells were incubated with fluorescein-labeled nucleotides without terminal transferase. For assessment of advanced fragmentation of DNA (a marker of advanced apoptosis), genomic DNA was isolated by standard phenol:chloroform extraction and samples corresponding to $10^{6} \mathrm{PMNs}$ were analyzed in $1.5 \%$ agarose gel electrophoresis as described previously. ${ }^{45}$

Purification and activation of gingipains. Arginine-specific (HRgpA and $\mathrm{RgpB}$ ) and lysine-specific (Kgp) gingipains were purified from the $P$. gingivalis HG66 strain culture fluid as described previously. ${ }^{46,47}$ Purity of each enzyme was checked by SDS-PAGE. The amount of active enzyme in purified gingipains was determined by active site titration using Phe-Pro-Arg-chloromethyl ketone and Z-FKck as active site titrants for Rgps and Kgp, respectively. ${ }^{48}$ The same inhibitors were used to obtain inactivated gingipains with covalently modified active site cysteine residues.

As cysteine proteinases, gingipains require pretreatment with a reducing agent to become active enzymes. Therefore, stock solutions of gingipains were diluted in $20 \mathrm{mM}$ HEPES, $5 \mathrm{mM} \mathrm{CaCl}_{2}$, pH 8.0, supplemented with $10 \mathrm{mM}$ cysteine to a final enzyme concentration of $1.2 \mu \mathrm{M}$ and incubated at $37^{\circ} \mathrm{C}$ for $15 \mathrm{~min}$. The activated gingipains were then diluted $1: 1(\mathrm{v} / \mathrm{v})$ with culture media to obtain a $600 \mathrm{~nm}$ working solution and diluted to appropriate final concentrations using media and cell suspensions.

Clostripain activation. Lyophilized clostripain from Clostridium histolyticum (Sigma) was dissolved in $1 \mathrm{~mm} \mathrm{CaCl} 2$ in $\mathrm{H}_{2} \mathrm{O}$ at $2 \mathrm{mg} / \mathrm{ml}$, aliquoted and stored frozen. Before use, the enzyme was diluted 50 -fold in $1 \mathrm{mM} \mathrm{CaCl}$ supplemented with $2.5 \mathrm{~mm}$ DTT and activated at $37^{\circ} \mathrm{C}$ for $2 \mathrm{~h}$. The activated clostripain was then diluted $1: 1(\mathrm{v} / \mathrm{v})$ with medium to obtain a $20 \mu \mathrm{g} / \mathrm{ml}$ working solution, which was mixed 1:1 (v/v) with cell suspensions.

Treatment of PMNs with proteinases. PMNs $\left(15 \times 10^{6} / \mathrm{ml}\right)$, either fresh or apoptotic, were suspended in RPMl 1640 supplemented with L-glutamine $(2 \mathrm{mM})$, gentamycin $(50 \mu \mathrm{g} / \mathrm{ml})$, and human serum $(10 \%)$ or BSA $(0.5 \%)$. Cells were incubated for $1 \mathrm{~h}$ at $37^{\circ} \mathrm{C}$ with activated, nonactivated or active site blocked gingipains (at final concentration of $300 \mathrm{nM}$ ), activated or nonactivated clostripain $(200 \mathrm{nM}), \mathrm{CG}(0.1,1.0$, and $10 \mu \mathrm{M}), \mathrm{NE}(0.1,0.5$, and $2 \mu \mathrm{M})$, thrombin $(50 \mathrm{nM})$ (Calbiochem), and trypsin $(4 \mu \mathrm{M})$ (Gibco) along with appropriate untreated controls in a humidified atmosphere containing $5 \% \mathrm{CO}_{2}$. After the incubation, PMNs were washed once in complete medium, harvested by centrifugation $(280 \times g, 10 \mathrm{~min}$, 
$4^{\circ} \mathrm{C}$ ) and resuspended in the complete medium, and subjected to phagocytosis by macrophages (hMDM) at a ratio of $20: 1$ (PMN : hMDM).

Phagocytosis of PMNs: MPO assay. A suspension of $2 \times 10^{6}$ apoptotic or fresh PMNs in complete medium was added to hMDM at the hMDM : PMN ratio in the range from $1: 0.4$ to $1: 100$ in a 24-well culture plate and incubated for $2 \mathrm{~h}$ in a humidified atmosphere containing $5 \% \mathrm{CO}_{2}$ at $37^{\circ} \mathrm{C}$. The monolayer was then washed vigorously with ice-cold PBS to remove unphagocytosed PMN, including those that were only macrophage-surface associated. The hMDM monolayer was fixed at room temperature with $2.5 \%$ glutaraldehyde for $15 \mathrm{~min}$, washed twice with PBS and treated with a $1: 1(\mathrm{v}: \mathrm{v})$ solution of dianisidine $(1.25 \mathrm{mg} / \mathrm{ml})$, and $0.05 \%$ $\mathrm{H}_{2} \mathrm{O}_{2}$ to detect $\mathrm{PMN}$-derived MPO activity serving as a marker for ingested PMNs. The dianisidine $/ \mathrm{H}_{2} \mathrm{O}_{2}$ solution was then replaced with PBS and the number of phagocytosed PMN per 100 macrophages per well was counted using a contrastphase microscopy at $\times 40$ magnification. The phagocytic index was calculated as the mean percentage of macrophage participating in PMN phagocytosis in replicated wells.

Phagocytosis of PMNs: elastase activity assay. Incubation of macrophages with PMNs was performed as described above. After washing off nonengulfed PMNs, the macrophages monolayer was lysed with $0.1 \%$ hexadecyltrimethyl ammonium bromide $(\mathrm{CTAB})$ at $37^{\circ} \mathrm{C}$ for $15 \mathrm{~min}$. Lysate $(100 \mu$ l) was transferred to a 96-well plate with four replicates, followed by the addition of $100 \mu \mathrm{l}$ of $1 \mathrm{mM}$ solution of $N$-methoxysuccinyl-Ala-Ala-Pro-Val-pnitroanilide in $0.2 \mathrm{M}$ Tris- $\mathrm{HCl}, \mathrm{pH} 7.5$. Hydrolysis of the substrate by PMN elastase was measured as the increase in absorbance at $405 \mathrm{~nm}$ after incubation at $37^{\circ} \mathrm{C}$ for 30 min using a microplate reader (Molecular Devices, Sunnyvale, CA, USA). The activity was expressed as an increase in absorbance at $\mathrm{OD}_{405 \mathrm{~nm}}$ in milliunits per min $\left(\mathrm{mOD}_{405} \mathrm{~nm} / \mathrm{min}\right.$ ). As a positive control, various numbers of PMN were added to wells with adherent macrophages, the mixture lysed with detergent $(0.1 \%$ CTAB) (Sigma) and the lysate assayed for PMN elastase activity. In addition, the lysates of the macrophage monolayer, which had not been exposed to PMN were used in each experiment as a negative control. Routinely, macrophages alone were found negative for elastase activity.

Phagocytosis of PMNs: flow cytometry, confocal microscopy, and TEM. Instantly after isolation, PMNs were labeled with PKH26 (red), according to the manufacturer's protocol (Sigma Chemical Co.). Cells were used directly after staining or cultured to undergo apoptosis. Treatment of PMNs with gingipains and incubation with macrophages were performed as described above. After washing off nonengulfed PMNs, macrophages were detached by a routine trypsinization procedure with trypsin/EDTA solution (Invitrogen) and collected for flow cytometry analysis (FACScan, Becton Dickinson). Phagocytosis of apoptotic and fresh PMNs was determined by the presence of PKH26-positive cells within macrophage population defined by FSC/SSC signals. A similar procedure, excluding trypsinization, was used for the confocal microscopy analysis. Briefly, macrophages cultured on coverslips were co-incubated with PKH26-labeled PMNs. After washing off nonengulfed PMNs, cell were fixed with paraformaldehyde and analyzed using a Bio-Rad MRC1024 confocal microscope equipped with an $\mathrm{Ar}-\mathrm{Kr}$ laser (ALC). A PlanApo $60 \times$ NA1.4 oil immersion lens was used.

For TEM analysis, the trypsinized MDMs were fixed at room temperature with $2.5 \%$ glutaraldehyde in $0.1 \mathrm{M} \mathrm{PBS}$ buffer at $\mathrm{pH} 7.4$ for $60 \mathrm{~min}$. After rinsing with $0.1 \mathrm{M}$ PBS, $(24 \mathrm{~h}$ ) cells were postfixed with $1 \%$ osmium tetroxide for $100 \mathrm{~min}$. After dehydration in an ethanol gradient and propylene oxide, the cells were embedded in Epon resin. Ultrathin sections were cut with LKB-NOVA microtome and subsequently, counterstained with $9 \%$ uranyl acetate in alcoholic solution and Reynolds solution. The sections were examined and photographed in a JEM 1200 EX electron microscope at $80 \mathrm{kV}$.

Phagocytosis of PMNs: TUNEL and flow cytometry. In order to determine phagocytosis of apoptotic PMNs, TUNEL labeling was performed on fixed and permeabilized macrophages fed with neutrophils. Treatment of PMNs with gingipains and incubation with macrophages were performed as described above. After washing off nonengulfed PMNs, macrophages were detached by routine trypsinization with trypsin/EDTA (Invitrogen), collected, and centrifuged. TUNEL reactions were then performed according to the manufacturer's recommendations (In Situ Cell Death Detection Kit, Roche). Samples were analyzed using a FACScan flow cytometer (Becton Dickinson). As a negative control, cells were incubated with fluorescein-labeled nucleotides without terminal transferase. Phagocytosis of apoptotic PMNs was determined by the presence of TUNEL-positive cells within macrophage population defined by FSC/SSC signals.

Effects of mAbs. Both partners in phagocytosis were pretreated with specific mAbs to block either the receptor on hMDMs or the recognition signal on target cells. All experiments were performed at the $1: 20$ (hMDMs : PMN) ratio. hMDM in 24-well plates were washed and the following mAbs in $0.5 \mathrm{ml}$ of RPMl 1640 supplemented with L-glutamine $(2 \mathrm{mM})$, gentamycin $(50 \mu \mathrm{g} / \mathrm{ml})$, and BSA $(0.5 \%)$ were added to each well at the indicated final concentration: anti-CD36 (Becton Dickinson, clone CB38, $100 \mu \mathrm{g} / \mathrm{ml}$ ); anti-TSP (Lab Vision Co. Clone A4.1, $100 \mu \mathrm{g} / \mathrm{ml}$ ); anti-CRT (Becton Dickinson, clone 16, $10 \mu \mathrm{g} / \mathrm{ml}$ ); anti-CD14 (Monosan, clone MEM-18, 2 $\mu \mathrm{g} / \mathrm{ml}$ ). The plates were incubated for $30 \mathrm{~min}$ at $4^{\circ} \mathrm{C}$, followed by the phagocytosis assay performed with standard conditions. Similarly, to block ICAM3 as a ligand for recognition and uptake by hMDMs, PMN suspension of fresh, or apoptotic cells, or proteinase-pretreated cells at a density of $2 \times 10^{7}$ cells $/ \mathrm{ml}$ in RPMI 1640 supplemented with L-glutamine $(2 \mathrm{mM})$, gentamycin $(50 \mu \mathrm{g} / \mathrm{ml})$, and BSA $(0.5 \%)$ was preincubated with anti-ICAM3 $\mathrm{mAb}$ (Calbiochem, clone 186-2G9, $40 \mu \mathrm{g} / \mathrm{ml}$ ) for $30 \mathrm{~min}$ at $4^{\circ} \mathrm{C}$ and PMN uptake by hMDMs was determined using standard conditions.

Effects of PAR-2 agonist peptide and soluble inhibitors of apoptotic cell uptake. The synthetic PAR-2 agonist peptide H-SLIGKV-NH ${ }_{2}$, corresponding to the tethered ligand (a kind gift from Dr Rob Pike, Monash University, Australia) and various inhibitors of apoptotic cells uptake were used to pretreat interacting cells and/or were included in the interaction medium. The PAR-2 agonist peptide $(100 \mathrm{nM})$, methylamine-treated $\alpha_{2}$ macroglobulin $\left(\alpha_{2} \mathrm{M}^{*}\right)(100 \mu \mathrm{g} / \mathrm{ml})$ (Athens Research and Technology, Athens, GA, USA), sCD91 (10 $\mu \mathrm{g} / \mathrm{ml})$ (BioMac $\mathrm{GmbH}$, Leipzig, Germany), tetrapeptide RGDS (2 mM), and the control peptide RGES (2 mM) (both from Sigma) were made up in RPMI 1640 before being added to the hMDMs to achieve the concentration listed above. hMDMs were incubated for $30 \mathrm{~min}$ at $4^{\circ} \mathrm{C}$ before PMNs were added for phagocytosis at the $1: 20$ (hMDM : PMN) ratio. PS or PC (Avanti Polar Lipids Inc.) liposomes were freshly prepared from lyophilized stock by resuspension in PBS and brief sonication (a hand-held sonicator, model UP5OH, Dr Hielscher $\mathrm{GmbH}, 10 \times 1$ s pulse, $50 \mathrm{~W}, 30 \mathrm{kHz}$ ). The final concentration in culture media was $10 \mu \mathrm{M}$.

Immunofluorescence staining of PMNs and flow cytometry analysis. For staining with anti-CD31, PMNs $\left(2 \times 10^{5} /\right.$ sample $)$ were resuspended in $\mathrm{PBS} / 0.5 \% \mathrm{BSA}$ and incubated with $\mathrm{PE}$-conjugated anti-CD31 $\mathrm{mAb}$ or isotype control (both from BD Pharmingen) for $30 \mathrm{~min}$ at $4^{\circ} \mathrm{C}$. After washing with cold PBS $/ 0.5 \% \mathrm{BSA}$, the cells were resuspended in $400 \mu$ l of PBS/0.5\%BSA and analyzed by flow cytometry. Flow cytometry analysis was performed using a FACScan cytometer (Becton Dickinson). Forward and side scatter signals were used to gate for morphologically normal PMNs and $10^{4}$ cells were acquired. The analysis was performed using the CellQuest program to determine the percentage and mean fluorescence intensity of positive cells.

Cell culture and measurement of TNF- $\alpha$ concentration. For the cytokine production assay, hMDM were cultured in a 24-well plate $\left(1 \times 10^{5}\right.$ cells per well) in a humidified atmosphere containing $5 \% \mathrm{CO}_{2}$ at $37^{\circ} \mathrm{C}$. In some cultures, fresh or apoptotic PMNs, untreated or pretreated with RgpB were added $\left(2 \times 10^{6} \%\right.$ $0.5 \mathrm{ml} /$ well). Additionally, macrophages were stimulated with LPS from Escherichia coli 0127:B8 (Sigma) at a final concentration of $2 \mathrm{ng} / \mathrm{ml}$. After $18 \mathrm{~h}$ incubation, supernatants were collected and assayed for TNF- $\alpha$ concentration by ELISA using an OptEIA TNF Set (Pharmingen), according to the instructions provided with the set of antibodies. The assay was sensitive down to a TNF- $\alpha$ concentration of $7 \mathrm{pg} / \mathrm{ml}$.

Statistics. The data are presented as means \pm S.D. All statistics were calculated using GraphPad Prism (version 2.0; GraphPad, San Diego, CA, USA). Non-parametric tests were applied throughout and calculated $P$-values are shown in the figures. They reflect the statistical significance of the difference in comparison to appropriate control of nontreated cells unless indicated otherwise.

\section{Acknowledgements}

We are indebted to Drs Barbara Gajkowska and Michal Walski (Laboratory of Cell Ultrastructure, Medical Research Center, Polish Academy of Sciences, Warsaw, 
Poland), and Dr Jerzy Doliwa-Dobrucki (Faculty of Biotechnology, Jagiellonian University) for TEM and confocal microscope analysis, respectively. Dr Ky-Anh Nguyen is acknowledged for fruitful discussion and critical reading of the manuscript. This work was supported in part by Grants 6 P04A 06019 and 6 P04A 04717 awarded to KG and JP, respectively, by the State Committee for Scientific Research (KBN, Warsaw, Poland), and by the National Institutes of Health (NIH, USA) funding to JT. JP is recipient of an award SUBSYDIUM PROFESORSKIE from the Foundation for Polish Science (FNP, Warszawa).

The authors have no conflicting financial interests.

1. Fadok VA, de Cathelineau A, Daleke DL, Henson PM, Bratton DL. Loss of phospholipid asymmetry and surface exposure of phosphatidylserine is required for phagocytosis of apoptotic cells by macrophages and fibroblasts. J Biol Chem 2001; 276: 1071-1077.

2. Krahling S, Callahan MK, Williamson P, Schlegel RA. Exposure of phosphatidylserine is a general feature in the phagocytosis of apoptotic lymphocytes by macrophages. Cell Death Differ 1999; 6: 183-189.

3. Somersan S, Bhardwaj N. Tethering and tickling: a new role for the phosphatidylserine receptor. J Cell Biol 2001; 155: 501-504.

4. Savill J, Dransfield I, Gregory C, Haslett C. A blast from the past: clearance of apoptotic cells regulates immune responses. Nat Rev Immunol 2002; 2: 965-975.

5. Lauber K, Blumenthal SG, Waibel M, Wesselborg S. Clearance of apoptotic cells: getting rid of the corpses. Mol Cell 2004; 14: 277-287.

6. Fadok VA, Bratton DL, Henson PM. Phagocyte receptors for apoptotic cells: recognition, uptake, and consequences. J Clin Invest 2001; 108: 957-962.

7. Hoffmann PR, deCathelineau AM, Ogden CA, Leverrier Y, Bratton DL, Daleke DL et al. Phosphatidylserine (PS) induces PS receptor-mediated macropinocytosis and promotes clearance of apoptotic cells. J Cell Biol 2001; 155: 649-659.

8. Savill J, Haslett C. Fate of neutrophils. In: Hellewell PG, Williams TJ (eds). Immunopharmacology of Neutrophils. Academic Press Inc.: New York, 1994, pp 295-314.

9. Miyasaki KT. The PMN: mechanisms of controlling periodontal bacteria. J Periodontol 1991; 62: 761-774.

10. Deas DE, Mackey SA, McDonnell HT. Systemic disease and periodontitis: manifestations of PMN dysfunction. Periodontol 2003; 2000: 32:82-32104.

11. Buchmann R, Hasilik A, Nunn ME, Van Dyke TE, Lange DE. PMN responses in chronic periodontal disease: evaluation by gingival crevicular fluid enzymes and elastase-alpha-1proteinase inhibitor complex. J Clin Periodontol 2002; 29: 563-572.

12. Buchmann R, Hasilik A, Van Dyke TE, Lange DE. Amplified crevicular leukocyte activity in aggressive periodontal disease. J Dent Res 2002; 81: 716-721.

13. Kantarci A, Oyaizu K, Van Dyke TE. PMN-mediated tissue injury in periodontal disease pathogenesis: findings from localized aggressive periodontitis. J Periodontol 2003; 74: $66-75$.

14. Gamonal J, Sanz M, O'Connor A, Acevedo A, Suarez I, Sanz A et al. Delayed PMN apoptosis in chronic periodontitis patients. J Clin Periodontol 2003; 30: 616-623.

15. Crawford JM, Wilton JM, Richardson P. PMNs die in the gingival crevice, periodontal pocket, and oral cavity by necrosis and not apoptosis. J Periodontol 2000; 71: 1121-1129.

16. Savill J, Hogg N, Ren Y, Haslett C. Thrombospondin cooperates with CD36 and the vitronectin receptor in macrophage recognition of PMNs undergoing apoptosis. $J$ Clin Invest 1992; 90: 1513-1522.

17. Ren $Y$, Stuart L, Lindberg FP, Rosenkranz AR, Chen $Y$, Mayadas TN et al. Nonphlogistic clearance of late apoptotic PMNs by macrophages: efficient phagocytosis independent of beta 2 integrins. J Immunol 2001; 166: 4743-4750.

18. Fadok VA, Savill JS, Haslett C, Bratton DL, Doherty DE, Campbell PA et al. Different populations of macrophages use either the vitronectin receptor or the phosphatidylserine receptor to recognize and remove apoptotic cells. J Immunol 1992; 149: 4029-4035.

19. Devitt A, Pierce S, Oldreive C, Shingler WH, Gregory CD. CD14-dependent clearance of apoptotic cells by human macrophages: the role of phosphatidylserine. Cell Death Differ 2003; 10: 371-382

20. Murphy JF, McGregor JL, Leung LL. Senescent human PMN binding to thrombospondin (TSP): evidence for a TSP-independent pathway of phagocytosis by macrophages. $\mathrm{Br} \mathrm{J}$ Haematol 1998; 102: 957-964.

21. Mitchell S, Thomas G, Harvey K, Cottell D, Reville K, Berlasconi G et al. Lipoxins, aspirintriggered epi-lipoxins, lipoxin stable analogues, and the resolution of inflammation: stimulation of macrophage phagocytosis of apoptotic PMNs in vivo. J Am Soc Nephrol 2002; 13: 2497-2507.

22. Kuijpers TW, Maianski NA, Tool AT, Becker K, Plecko B, Valianpour F et al. PMNs in Barth syndrome (BTHS) avidly bind annexin-V in the absence of apoptosis. Blood 2004; 103 3915-3923.

23. Pozo P, Valenzuela MA, Melej C, Zaldivar M, Puente J, Martinez B et al. Longitudinal analysis of metalloproteinases, tissue inhibitors of metalloproteinases and clinical parameters in gingival crevicular fluid from periodontitis-affected patients. J Periodontal Res 2005; 40: 199-207.
24. Eley BM, Cox SW. Correlation between gingivain/gingipain and bacteria dipeptidyl peptidase activity in gingival crevicular fluid and periodontal attachment loss in chronic periodontitis patients. A 2-year longitudinal study. J Periodontol 1996; 67: 703-716.

25. Armitage GC, Jeffcoat MK, Chadwick DE, Taggart Jr EJ, Numabe $Y$, Landis JR et al. Longitudinal evaluation of elastase as a marker for the progression of periodontitis. $J$ Periodontol 1994; 65: 120-128.

26. Mailhot JM, Potempa J, Stein SH, Travis J, Sterrett JD, Hanes PJ et al. A relationship between proteinase activity and clinical parameters in the treatment of periodontal disease. $J$ Clin Periodontol 1998; 25: 578-584.

27. Fadok VA, Bratton DL, Guthrie L, Henson PM. Differential effects of apoptotic versus lysed cells on macrophage production of cytokines: role of proteases. J Immunol 2001; 166 : 6847-6854.

28. Dollery CM, Owen CA, Sukhova GK, Krettek A, Shapiro SD, Libby P. PMN elastase in human atherosclerotic plaques: production by macrophages. Circulation 2003; 107: 2829-2836.

29. Belaaouaj A, McCarthy R, Baumann M, Gao Z, Ley TJ, Abraham SN et al. Mice lacking PMN elastase reveal impaired host defense against gram negative bacterial sepsis. Nat Med 1998; 4: 615-618.

30. Benarafa C, Cooley J, Zeng W, Bird PI, Remold-O'Donnell E. Characterization of four murine homologs of the human ov-serpin monocyte PMN elastase inhibitor MNEI (SERPINB1). J Biol Chem 2002; 277: 42028-42033.

31. Martin SJ, Reutelingsperger P, McGahon AJ, Rader JA, van Schie RC, Laface DM et al. Early redistribution of plasma membrane phosphatidylserine is a general feature of apoptosis regardless of the initiating stimulus: inhibition by overexpression of $\mathrm{Bcl}-2$ and $\mathrm{Abl}$. J Exp Med 1995; 182: 1545-1556.

32. Lourbakos A, Chinni C, Thompson P, Potempa J, Travis J, Mackie EJ et al. Cleavage and activation of proteinase-activated receptor-2 on human PMNs by gingipain- $R$ from Porphyromonas gingivalis. FEBS Lett 1998; 435: 45-48.

33. Chen JM, Rawlings ND, Stevens RA, Barrett AJ. Identification of the active site of legumain links it to caspases, clostripain and gingipains in a new clan of cysteine endopeptidases. FEBS Lett 1998; 441: 361-365.

34. Brown S, Heinisch I, Ross E, Shaw K, Buckley CD, Savill J. Apoptosis disables CD31mediated cell detachment from phagocytes promoting binding and engulfment. Nature 2002; 418: 200-203.

35. Bangalore N, Travis J. Comparison of properties of membrane bound versus soluble forms of human leukocytic elastase and cathepsin G. Biol Chem Hoppe Seyler 1994; 375 (10): $659-666$.

36. Hermant B, Bibert S, Concord E, Dublet B, Weidenhaupt M, Vernet T et al. Identification of proteases involved in the proteolysis of vascular endothelium cadherin during PMN transmigration. J Biol Chem 2003; 278: 14002-14012.

37. Arur S, Uche UE, Rezaul K, Fong M, Scranton V, Cowan AE et al. Annexin I is an endogenous ligand that mediates apoptotic cell engulfment. Dev Cell 2003; 4: 587-598.

38. Gregory CD, Devitt A. The macrophage and the apoptotic cell: an innate immune interaction viewed simplistically? Immunology 2004; 113: 1-14.

39. Hart SP, Ross JA, Ross K, Haslett C, Dransfield I. Molecular characterization of the surface of apoptotic PMNs: implications for functional downregulation and recognition by phagocytes. Cell Death Diff 2000; 7: 493-503.

40. Voll RE, Hermann M, Roth EA, Stach C, Kalden JR, Girkontaite I. Immunosuppressive effects of apoptotic cells. Nature 1997; 390: 350-351.

41. Bzowska M, Guzik K, Barczyk K, Ernst M, Flad HD, Pryjma J. Increased IL-10 production during spontaneous apoptosis of monocytes. Eur J Immunol 2002; 7 2011-2020.

42. Kim S, Elkon KB, Ma X. Transcriptional suppression of interleukin-12 gene expression following phagocytosis of apoptotic cells. Immunity 2004; 21: 643-653.

43. Vandivier RW, Fadok VA, Hoffmann PR, Bratton DL, Penvari C, Brown KK et al. Elastasemediated phosphatidylserine receptor cleavage impairs apoptotic cell clearance in cystic fibrosis and bronchiectasis. J Clin Invest 2002; 109: 661-670.

44. Imamura T. The role of gingipains in the pathogenesis of periodontal disease. J Periodontol 2003; 74: 111-118.

45. Guzik K, Bzowska M, Dobrucki J, Pryjma J. Heat-shocked monocytes are resistant to Staphylococcus aureus-induced apoptotic DNA fragmentation due to expression of HSP72. Infect Immun 1999; 67: 4216-4222.

46. Pike R, McGraw W, Potempa J, Travis J. Lysine- and arginine-specific proteinases from Porphyromonas gingivalis: isolation and evidence for the existence of complexes with hemagglutinins. J Biol Chem 1994; 269: 406-411.

47. Potempa J, Mikolajczyk-Pawlinska J, Brassell D, Nelson D, Thogersen IB, Enghild JJ et al. Comparative properties of two cysteine proteinases (gingipain Rs), the products of two related but individual genes of Porphyromonas gingivalis. J Biol Chem 1998; 273: 21648-21657.

48. Potempa J, Pike R, Travis J. Titration and mapping of the active site of cysteine proteinases from Porphyromonas gingivalis (Gingipains) using peptidyl chloromethanes. Biol Chem 1997; 378: 223-230. 